\section{Bone marrow niche dysregulation in myeloproliferative neoplasms}

\author{
Natalia Curto-Garcia, Claire Harrison and Donal P McLornan \\ Department of Hematology, Guy's and St Thomas' NHS Foundation Trust, London, UK
}

\section{ABSTRACT}

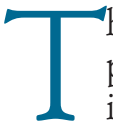
he bone marrow niche is a complex and dynamic structure composed of a multitude of cell types which functionally create an interactive network facilitating hematopoietic stem cell development and maintenance. Its specific role in the pathogenesis, response to therapy, and transformation of myeloproliferative neoplasms has only recently been explored. Niche functionality is likely affected not only by the genomic background of the myeloproliferative neoplasm-associated mutated hematopoietic stem cells, but also by disease-associated 'chronic inflammation', and subsequent adaptive and innate immune responses. 'Cross-talk' between mutated hematopoietic stem cells and multiple niche components may contribute to propagating disease progression and mediating drug resistance. In this timely article, we will review current knowledge surrounding the deregulated bone marrow niche in myeloproliferative neoplasms and suggest how this may be targeted, either directly or indirectly, potentially influencing therapeutic choices both now and in the future.

\section{Introduction}

'Philadelphia chromosome negative' myeloproliferative neoplasms (MPN) are a group of relatively rare hematologic diseases characterized by a clonal proliferation of blood cells, most commonly secondary to acquired hematopoietic stem cell (HSC) mutations that directly or indirectly induce upregulation of the JAK-STAT pathway. The 2016 World Health Organization consensus recognizes the following categories under the MPN classification: chronic myeloid leukemia $B C R-A B L^{+}$, chronic neutrophilic leukemia, essential thrombocythemia (ET), polycythemia vera (PV), primary myelofibrosis (PMF) (which includes both the prefibrotic/early stage and overt fibrotic stage), chronic eosinophilic leukemia not otherwise specified, and MPN-unclassifiable. ${ }^{1}$ Recent analyses estimate the incidence rates of the classical 'Philadelphia negative'-MPN PV, ET and PMF as 0.7-2.6 cases, 0.34-1.7 cases and $0.1-1.0$ cases per 100,000 patients-per-year, respectively. ${ }^{2}$ Median age at diagnosis is variable, estimated at between 69-76 years for PMF, 65-74 years for PV, and 6473 years for ET, although MPN has been described in many younger patients and can manifest at any age. ${ }^{3}$ Regarding clinical features, these disorders produce a markedly heterogeneous clinical phenotype. For example, in PMF, patients may range from those lacking any discernible symptomatology to those describing debilitating constitutional symptoms, abdominal discomfort due to splenomegaly, bone pain, and symptomatic anemia, amongst others. The most common complications linked to MPN are thrombotic and hemorrhagic events and an inherent risk of leukemic transformation that is dependent upon the underlying MPN phenotype; this risk is higher for PMF (estimated at a range of $10-20 \%$ in the first 10 years from diagnosis) and much lower for both PV $(2.3 \%)$ and ET $(1 \%) .{ }^{4}$ These figures reflect historical data, and it is likely that with the move away from consecutive cytotoxic therapeutic approaches, blastic transformation rates may well be lower.

Following the pivotal reports in 2005 by four different research groups concerning the prevalence of the acquired somatic mutation JAK2 V617F in MPN, knowledge of the mutational landscape continues to expand. ${ }^{5.8}$ The JAK2 V617F mutation is present in approximately $98 \%$ of $\mathrm{PV}$ patients, and has an estimated incidence in ET and MF of $50 \%$ and $60 \%$, respectively. Mutations in the thrombopoietin receptor $(M P L)$ are described in approximately $3 \%$ of ET and $5-8 \%$ of MF cases, whereas mutations in calreticulin (CALR) are evident in $25 \%$ of ET and $30 \%$ of MF
Ferrata Storti Foundation
Haematologica 2020
Volume 105(5):1189-1200

Correspondence:

CLAIRE HARRISON

claire.harrison@gstt.nhs.uk

Received: November 18, 2019.

Accepted: February 6, 2020.

Pre-published: April 2, 2020.

doi:10.3324/haematol.2019.243121

Check the online version for the most updated information on this article, online supplements, and information on authorship \& disclosures: www.haematologica.org/content/105/5/1189

(C)2020 Ferrata Storti Foundation

Material published in Haematologica is covered by copyright. All rights are reserved to the Ferrata Storti Foundation. Use of published material is allowed under the following terms and conditions:

https://creativecommons.org/licenses/by-nc/4.0/legalcode. Copies of published material are allowed for personal or internal use. Sharing published material for non-commercial purposes is subject to the following conditions:

https://creativecommons.org/licenses/by-nc/4.0/legalcode, sect. 3. Reproducing and sharing published material for commercial purposes is not allowed without permission in writing from the publisher. 
patients..$^{911} \mathrm{Up}$ to $20 \%$ with ET and up to $15 \%$ of patients with PMF lack detectable mutations in these three genes, as assessed by conventional assays; such patients are termed 'triple negative'. ${ }^{12-14}$ Lastly, comprehensive genomic analyses have revealed the presence of additional mutations that can appear before, simultaneously, or following the so-called 'driver mutations' (JAK2, CALR and MPL) in $\mathrm{PMF}$ and can affect a wide-array of key genes, such as those involved in epigenetic regulation (TET2, ASXL1, EZH2), splicing (SRSF2, U2AF1), and cellular signaling (SH2B3, PIAS3), some of which also affect prognosis. ${ }^{15}$

Multiple factors contribute to the dynamic complexity of the bone marrow niche in MPN, such as the inherent increase in pro-inflammatory cytokines, skewed adaptive and innate immune responses, and 'cross-talk' between the normal and mutated-HSC, endosteal and vascular niches and extracellular matrix. In this review, we will summarize current knowledge concerning bone marrow niche composition in health and how it differs in MPN. Likewise, as we gain further understanding of these dynamics, we will explore what potential there is for therapeutic intervention specifically targeting the niche to provide clinical benefit.

\section{Overview of the bone marrow niche in health}

It is evident that much remains to be elucidated concerning the dynamic BM microenvironment, both in normal physiological and disease states. Traditionally, the niche is conceived as being divided into individual compartments with bi-directional 'cross-talk' between the well-defined spatially organized HSC, multiple surrounding permissive cells, and the extracellular matrix (Figure 1). This concept was first delineated by Lord et al. and Schofield more than 40 years ago. ${ }^{16,17}$ The accumulated evidence demonstrates that multiple additional factors can influence, either directly or indirectly, this niche, such as microenvironmental oxygen tension variations, sympathetic nervous system activity, and endocrine signaling such as the estrogen pathway. ${ }^{18,19}$

Simplistically, the endosteal niche, which is highly vascularized, is considered to be where the "potent and primitive' HSC reside, rich in long-term (LT)-HSC. The pivotal paper by Nilsson et al. demonstrated that, following HSC 'transplantation' in mice, HSC 'homed' to the endosteum, with subsequent maintenance and promotion of HSC development. ${ }^{20}$ Later studies by Celso et al. and Xie et al. showed similar results. ${ }^{21,22}$ This niche is formed predominantly by osteoblasts (which mainly line the endosteal bone surface), osteoclasts, and a specific osteoblastic subpopulation known as spindle-shaped N-cadherin ${ }^{+}$ osteoblasts (SNO cells). Within the niche, both BM mesenchymal stem cells (BMSC) and the $\mathrm{N}$-cadherin ${ }^{+}$cell population play an indispensable role in HSC maintenance. Each of these cell populations and their interactions with each other (and with the HSC population) ultimately determines maintenance and proliferation of the hematopoietic stem/progenitor cell pool and downstream lineage differentiation.

Osteoblasts are derived from multipotent BMSC where-

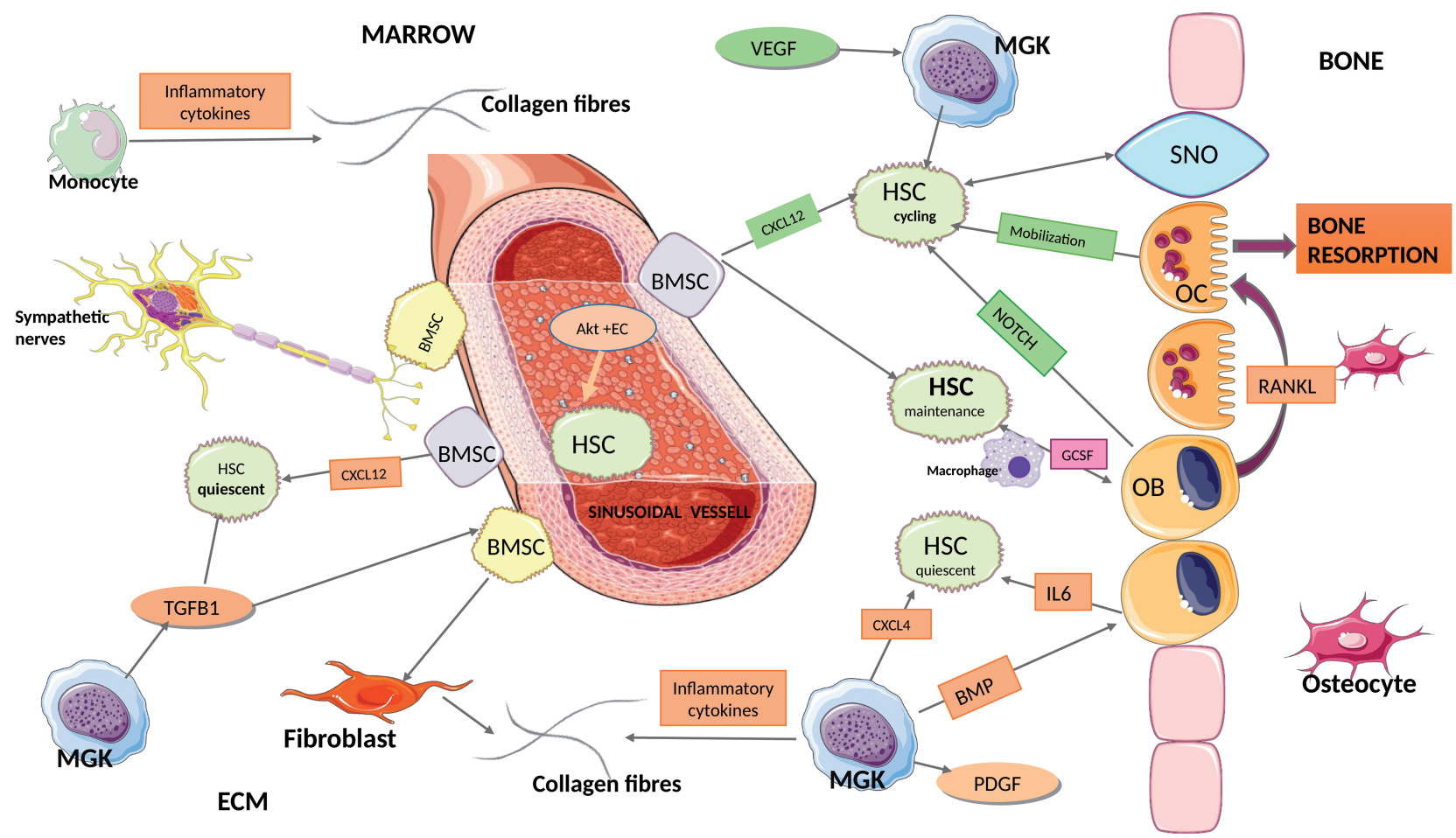

Figure 1. Hematopoietic stem cell (HSC) cycling is regulated by osteoclast (OC), osteoblast (OB) by NOTCH expression and spindle-shaped N-cadherin ${ }^{+}$osteoblast (SNO) cells. Different bone marrow mesenchymal cells (BMSC) participate in HSC regulation, such as CXCL12-abundant reticular (CAR) cells that stimulate HSC cycling by producing CXCL12. On the other hand, megakaryocytes (MGK) are activated by vascular endothelial growth factor (VEGF) and participate in the activation of HSC cycling. HSC maintenance is regulated by a reciprocal communication between OB and HSC. CAR cells also participate in this regulation. Finally, HSC quiescent is regulated by both the bone marrow niche (BMN) and the extracellular matrix (ECM), thus, OB and MGK interact in this control. The growth factor TGFb1 and, indirectly, the platelet-derived growth factor (PDGF) (by activating MGK) would participate in the HSC quiescent. Nestin ${ }^{+}$BMSC regulate the CXCL12 production and the sympathetic nerves contribute to BMN functionality. EC: endothelial cell. 
as osteoclasts originate from $\mathrm{CD} 34^{+}$hematopoietic cells. ${ }^{23}$ Early work showed that the two populations were functionally interdependent, e.g. osteoblasts constitutively expressed G-CSF and ${\mathrm{CD} 34^{+}}^{+}$hematopoietic cells enhanced IL- 6 production by osteoblasts hence stimulating further investigations into these interactions. ${ }^{24,25}$ It is accepted that, in general, osteoblast functionality plays an important role in HSC maintenance, in particular with regard to HSC trafficking. Regulatory roles depend upon osteoblastic differentiation stage, whereby the immature osteoblast progenitor population influences HSC maintenance/proliferation and the mature osteoblasts modulate their differentiation. ${ }^{26}$ In murine models, Calvi et al. demonstrated that osteoblastic cells influenced HSC functional capacity through NOTCH activation, and it was suggested that HSC are located in close physical proximity to SNO cells, although the role of $\mathrm{N}$-cadherin in these 'cell-cell' interactions remains under debate. ${ }^{27,28}$ Multiple soluble factors derived from the osteoblast population play a role in HSC pool fate, including CXCL12, angiopoietin-1 and osteopontin, in addition to multiple other cytokines/chemokines. ${ }^{29}$ CXCL12 is a CXC chemokine produced by stromal cells, the major source is from BMSC but also by osteoblasts influenced by circadian oscillations and there is evidence that CXCL12/CXCR4 signaling plays a pivotal role in modulation of HSC trafficking. ${ }^{30}$ In addition, the acidic matrix glycoprotein osteopontin is produced by pre-osteoblasts and osteoblasts and negatively regulates both HSC pool 'size' and egress. ${ }^{27,31}$ Of note, osteoblasts play an additional role in T lymphopoiesis, whereby DLL4 on the cell surface is pivotal for the production of 'thymic seeding' $T$ progenitors. ${ }^{32}$

As introduced above, osteoclasts derived from monocyte-macrophage lineage cells in the presence of receptor activator of nuclear factor-кB-ligand and macrophage colony-stimulating factor play multiple regulatory roles within the niche in addition to their bone resorption characteristics. $^{33}$ Kollet et al. demonstrated that, through endosteal component degradation, osteoclasts can promote HSC mobilization. ${ }^{34}$ However, the literature also includes contrasting evidence concerning their exact role within the HSC niche, which is most likely context dependent. For example, using the osteopetrotic 'OC/OC'-murine model, absence of functional osteoclasts induced a defective HSC niche with increased mesenchymal precursors, impaired osteoblast development, and resultant aberrant HSC homing. ${ }^{35}$ However, Miyamoto et al. evaluated hematopoietic activity in three murine models without osteoclasts and showed that HSC mobilization was, in fact, similar, or indeed higher, than that of wild-type animals, suggesting that osteoclasts are not essential for HSC mobilization. ${ }^{36}$ Lastly, there is a great deal of cross-talk and interdependency between the osteoblast and osteoclast populations. It has also been shown that osteoclasts can act as antigen presenting cells and activate both $\mathrm{CD}^{+}$and $\mathrm{CD}^{+}{ }^{+}$cells. $^{37}$

The vascular niche is the other pivotal component of the bone marrow niche and broadly encompasses thin-walled sinusoidal blood vessels, arterioles, transition zone vessels, endothelial cells (that also produce CXCL12), stromal elements, fibronectin, and collagen. Functionally, interactions between these perivascular elements determine both HSC dormancy/expansion and migration properties. By way of example, Akt activation in endothelial cells following $\mathrm{mTOR}$ recruitment induces upregulation of specific angiocrine factors which promotes expansion of cells with LT-HSC repopulation capacity. ${ }^{38}$ Cell-cell contact also appears key. For example, E-selectin expression by endothelial cells in the vascular niche can regulate HSC dormancy and HSC proliferation..$^{39}$ Moreover, the vascular niche provides an environment rich in multiple proinflammatory chemokines/cytokines, which contribute to niche maintenance. The so-called 'hypoxic-gradient' plays a major role in spatial HSC location within the vascular niche. In this way, quiescent HSC preferentially locate to small arterioles, unsheathed by rare NG2-pericytes, predominantly found in the endosteal bone region. HSC tend to exhibit a strong hypoxic profile, promoting quiescence, irrespective of localization. ${ }^{40,41}$ Likewise, in those situations whereby the sinusoids are under stress induced by, for example, myeloablative chemotherapy or irradiation, the endosteal niche becomes an important host of HSC and promotes quiescence. ${ }^{42}$

Bone marrow mesenchymal stem cells encompass a diverse group of cells with multipotent differentiation and self-renewal properties indispensable for HSC maintenance. BMSC can interact in a pleotropic fashion with HSC including direct cell-cell interaction and by the altered production of cytokines and cell markers. ${ }^{43}$ CXCL12-abundant reticular cells are a subpopulation of BMSC that produce CXCL12 and regulate the maintenance and quiescence of the HSC pool. Multiple other cell types, outside the remit of this review, contribute to the regulation of the niche including macrophages which modulate the CXCL12 pathway promoting HSC retention, and monocytic-lineage cells which regulate osteoblasts, facilitate HSC mobilization and also encourage a pro-inflammatory cytokine environment. ${ }^{31}$ Concerning the role of the sympathetic nervous system, Mendez-Ferrer et al. demonstrated that circulating HSC and their progenitors exhibit marked circadian fluctuations regulated by noradrenaline secretion by the sympathetic nervous system. ${ }^{30,44}$ Adrenergic signals via the beta(3)-adrenergic receptor mediate downregulation of CXCL12 and there is a close association between so-called Nestin ${ }^{+}$BMSC and adrenergic nerve fibers of the SNS with resultant regulation of HSC functionality and egress. This neuro-hematopoietic axis is exploitable as a therapeutic target, as will be discussed later.

With regard to the extracellular matrix (ECM), this is a non-cellular space that supports the integrity, proliferation and 'elasticity' of the entire bone marrow niche. It acts as a pivotal HSC 'regulator' and ECM-related components critically determine the functionality of HSC lodged within its confines. ${ }^{45}$ The 'core matrisome' is a complex structure that consists of up to 300 protein components, enzymes, and growth factors (e.g. TGF $\beta 1, P D G F$ and $V E G F$ ), and overall functionally drives maintenance of the HSC pool.

\section{Bone marrow niche / extracellular matrix disruption in myeloproliferative neoplams}

Myeloproliferative neoplasm-associated bone marrow niche homeostasis is disrupted on many levels which collectively can promote the proliferation, survival and migration of mutated MPN HSC. As described by Mead and Mullaly, both 'host' and extrinsic factors can influence MPN HSC behavior, and as the malignant clone expands, 
this favors MPN HSC growth over normal HSC expansion. ${ }^{46}$ Mullally et al. have described that JAK2V617F-LTHSC are capable of initiating and promoting the disease, giving a clonal advantage to dominate the niche against WT cells. In addition, mutated LT-HSC could induce fibrotic changes in the bone marrow niche in WT transplanted mouse models. ${ }^{47}$ Furthermore, Lundberg et al. proved elevated JAK2 expression levels impact negatively on the repopulation capacity of LT-HSC and will promote the disease expansion. ${ }^{48}$ Finally, acquisition of other mutations, such as TET2 deletions in JAK2 V617F-LT-HSC, gives a clonal advantage favoring the disease progression. ${ }^{49}$

Regarding the osteoblast-osteoclast axis, it is clear that aberrant functionality of the endosteal osteoblastic niche plays an important role in MPN maintenance and progression. For example, it has been shown in murine models that osteoblast expansion is functionally altered in MPN and promotes the development of fibrosis. ${ }^{50}$ Over time, disease-driven remodeling of the endosteal niche occurs, leading to a self-reinforcing 'leukemia-niche' with impaired normal hematopoiesis. Several mechanisms, as suggested by the authors, are implicated in dysregulated osteoblastic expansion, such as overstimulation of MSC driving production of functionally impaired osteoblasts, resultant direct 'cell-cell contact' with mutated MPN HSC, and up-regulated production of TPO, CCL3, TNF- $\beta$ and Notch, thus inducing a chronic state of 'inflammation'. ${ }^{51,52}$ Expression of CXCL12, essential for controlled HSC mobilization, as discussed above, is reduced due to this abnormal osteoblast functionality. Moreover, Spanoudakis et al. recently showed that monocytes derived from JAK2 V617F (heterozygote)-MPN cells had enhanced osteoclastformation ability compared to wild-type monocytes. An enriched osteoclast environment additionally favors $\mathrm{MPN}$-associated mutated cell population proliferation and survival. ${ }^{53}$ Collectively, these findings highlight the importance of the osteoblast-osteoclast axis and its disruption in MPN and how this may be therapeutically exploited.

Clonal-MPN cells additionally have the capacity to disrupt the finely balanced vascular niche. By way of example, JAK2-mutated endothelial cells promote the abnormal proliferation and survival of mutated-HSC whilst inhibiting normal HSC functionality. This occurs secondary to alterations within the CXCL12 and stem cell factor pathways. Vascular endothelial growth factor (VEGF), produced by both the endothelial cells and the 'mutated'HSC, supports neo-angiogenesis and increases both survival and proliferation of these HSC. Therefore, a selfreinforcing vascular niche also develops as a favorable environment for MPN mutated-HSC. ${ }^{54}$ Hypoxia-induced signaling also appears to influence HSC behavior by encouraging quiescence and influences long-term repopulating activity. ${ }^{55}$ Utilizing transgenic MPN-murine-models, it has been shown that downregulation of HIF-1 $\alpha$ induces an enhanced MPN phenotype reflected by increased leukocytosis and significant splenomegaly. ${ }^{56}$

Importantly, BMSC appear pivotal to the development and maintenance of the MPN phenotype. BMSC promote the abnormal expansion of osteoblasts as inflammatory 'myelofibrotic' cells; a conversion mediated by dysregulation of inflammatory signaling pathways with excess production of TGF- $\beta 1$, Notch, IL- 6 , IL- $1 \beta$ and TNF- $\beta$ and secondary to direct contact between the clonal MPN-HSC and BMSC. ${ }^{77}$ Schneider et al. has demonstrated that Gli1 ${ }^{+}-$ BMSC participate in the activation of myelofibroblasts. ${ }^{58}$
Ultimately, the overproduction of inflammatory 'myelofibrotic cells' contributes to progressive BM fibrosis observed in the advanced stages of these diseases. ${ }^{31}$ At the same time, excessive osteoblast production perpetuates clonal-MPN cell proliferation. ${ }^{50}$ Ramos et al. recently demonstrated that BMSC derived from MPN patients (mainly PV and ET) present an altered gene and immunophenotypic expression profile compared to those derived from healthy donors. In PV, BMSC show an overexpression of genes involved in cell differentiation and migration such as MYADM, Angiopoietin-1 expression and decreases in CXCL12; that are associated with 'cross-talk' between the mutated-HSC and BMSC. ${ }^{59}$ Angiopoietin-1 participates in both angiogenesis and the quiescence of the HSC. Osteoblast production of angiopoietin-1 facilitates interaction with Tie-2, resulting in increased adhesion of HSC to osteoblasts within the niche. ${ }^{60}$

More recently, other studies have explored the neurohematopoietic axis, demonstrating that the sympathetic nervous system influences bone marrow niche regulation. Arranz et al. elegantly showed that a local neuropathy occurs in MPN-BM, with a reduction in both Nestin ${ }^{+}$ BMSC and CXCL12 expression and promotion of $J A K 2^{+}$ HSC expansion. The relationship, if any, between this local neuropathy and the patient's symptomatology and phenotype is still not clear, although it has been described as a possible therapeutic target, as discussed below. ${ }^{31,61}$ Lastly, an increased understanding of the role of estrogen signaling is emerging. In normal HSC, it has been shown that estrogen receptor stimulation in vivo led to an increased proliferation of quiescent LT-HSC and tamoxifen induced apoptosis of short-term HSC and multipotent progenitors. In chronic MPN, JAK2-mutated murine models, tamoxifen led to preferential restoration of apoptosis in mutated-HSC. ${ }^{2}$

Regarding the ECM, clonal-HSC demonstrate dysregulated 'cross-talk' with augmented levels of cytokines and growth factors within the ECM, enhancing both disease establishment and progression. In MF, there is an intensified deposition of ECM components. Thus, highly fibrogenic TGF $\beta 1$ activates fibrosis deposition by two main routes: (i) skewing BMSC activation towards fibroblastic and osteoblastic genesis; and (ii) an augmented production of collagen. Moreover, TGF $\beta 1$ levels are intimately linked to megakaryocytic activity. ${ }^{63}$ Additional growth factors such as PDGF (platelet derived growth factor) and VEGF play a pivotal role in this unbalanced ECM-MPN marrow niche communication. PDGF promotes fibrogenesis by activating both megakaryocytes and fibroblasts whereas VEGF contributes towards megakaryocytic maturation and migration.

Other relevant modifiers of the MPN-associated ECM are matrix metalloproteinases (MMP) and Lysyl Oxidase (LOX). ${ }^{64}$ In MPN, Wang et al. demonstrated downregulation of MMP, supporting the accumulation of ECM substances. Focusing on MF, this study demonstrated decreased MMP3 levels which inversely correlated with increased fibrosis and enhanced expression of tissue inhibitors of the metalloproteinases..$^{65}$ Both $M M P 2$ and $M M P 9$ are highly expressed in MPN patients and are reduced after treatment with JAK inhibitors. ${ }^{66}$ LOX is a potent regulator of fibrogenesis and is involved in collagen cross-linking. Previous studies have demonstrated a link between deregulated megakaryocytic production of PDGF, TGF- $\beta 1$ and IL-1 $\beta$ and augmented LOX activity, 
with resultant collagen accumulation in $\mathrm{MF}^{64}$ Tadmor et al. demonstrated that, in MF, all LOX members genes are activated compared to the pattern seen in either ET or PV; postulating that this occurred during fibrogenesis. Of interest, LOXL1 was only expressed in MF, suggesting a relationship with advanced fibrosis. ${ }^{67}$

In summary, it is evident that the bone marrow niche is profoundly dysregulated on multiple, yet interacting levels, in MPN (Table 1). Mutated-MPN-HSC activate a cascade of dysregulated signaling and abnormalities in multiple key players across the niches, compromising functionality of both the osteoblastic and vascular niches and ECM. Consequently, these irregularities promote the abnormal proliferation inherent to these disease states. Although our knowledge of the MPN-associated dysregulated niche has increased in recent years, further studies are required to help understand how this niche can be successfully targeted in therapy.

\section{Direct or indirect targeting of the bone marrow niche in myeloproliferative neoplasms: is there a role?}

To date, the only curative treatment for MF remains allogeneic stem cell transplantation, although this is not a feasible option for many due to age, risk profile, co-morbidities, or lack of a suitable donor. ${ }^{68}$ Many clinicians have familiarity with the JAK1/JAK2 inhibitor (JAKi) ruxolitinib (Novartis, Switzerland), currently the only licensed agent in MF; which has demonstrated improvement in diseaserelated symptomatology, induced reductions in spleen size, and prolonged the overall survival $(O S)$ in many MF patients. ${ }^{69,70}$ Of note, ruxolitinib has also been used in both PV and ET, particularly in the setting of hydroxycarbamide resistance or intolerance. ${ }^{71.74}$ Many other agents have entered the clinical trial arena to address the multiple unmet needs, particularly when individuals are failing or become intolerant of standard therapies, including novel JAKi, BET-inhibitors, BCL-2 inhibitors, HDAC inhibitors, telomerase inhibitors, and MDM2 inhibitors. ${ }^{75-81}$ Regarding novel JAKi, pacritinib (which is also a FLT3 inhibitor) has been investigated in MF patients with thrombocytopenia showing improvements in splenic responses within both the PERSIST-I and -II studies. . $^{82,83}$ The drug was on clinical hold from 2016 due to concerns regarding cardiac toxicity, but following the Food and Drug Administration (FDA) review and removal of the clinical hold, the PAC203 study has now fully recruited and further studies are planned. Momelotinib, a JAK1/2 inhibitor, demonstrated anemia and transfusion responses in both the SIMPLIFY-1 and 2 clinical trials but it failed to meet the pre-defined clinical end points, although some patients demonstrated symptom, spleen and anemia responses. ${ }^{84,85}$ This agent will be compared on a randomized basis to danazol in the upcoming MOMEMTUM study. Fedratinib (Inrebic ${ }^{\circledR}$, Celgene, USA) is a more selective JAKi than ruxolitinib; both JAKARTA-1 and 2 trials showed this agent to have significant efficacy in MF

Table 1. Bone marrow niche in health and myeloproliferative neoplasm.

\begin{tabular}{|c|c|c|}
\hline & Bone marrow niche in health & Bone marrow niche in MPN \\
\hline $\begin{array}{l}\text { Endosteal niche: } \\
\text { Osteoblasts, Osteoclasts } \\
\text { and spindle-shaped } \\
\text { N-cadherin }{ }^{+} \text {osteoblast } \\
\text { cells }\end{array}$ & $\begin{array}{l}\text { - Maintenance, proliferation and differentiation of HSC. } \\
\text { - Osteoblasts: } \\
\text { - Interact with CD34+HSC by expressing GSCF and IL6. } \\
\text { - Regulate HSC trafficking by expression CXCL12, } \\
\text { angiopoietin-1 and osteopontin. } \\
\text { - Osteoclasts: } \\
\text { - Regulatory role. } \\
\text { - Bone resorption. } \\
\text { - Promote HSC mobilization. } \\
\text { - SNO cells: } \\
\text { - Cell-cell contact with HSC. }\end{array}$ & $\begin{array}{l}\text { Self-reinforcing of clonal cells. } \\
\text { - Osteoblasts: } \\
\text { - Abnormal OB expansion due to overstimulation by BMSC. } \\
\text { - Overproduction of inflammatory cytokines. } \\
\text { - Promotion of fibrogenesis. } \\
\text { - Reduction in CXCL12 expression. } \\
\text { - Osteoclasts: } \\
\text { - Abnormal stimulation by JAK2 positive monocytes. } \\
\text { - Favoring survival of clonal HSC. } \\
\text { - SNO: } \\
\text { - No clear role described yet. }\end{array}$ \\
\hline $\begin{array}{l}\text { Vascular niche: sinusoidal blood } \\
\text { vessels, endothelial cells, } \\
\text { stromal elements, fibronectin } \\
\text { and collagen }\end{array}$ & $\begin{array}{l}\text { - Regulate HSC migration . } \\
\text { - Expression of e-selectin by endothelial cells. } \\
\text { - Production of inflammatory chemokines and cytokines. } \\
\text { - Regulation of hypoxia status . } \\
\text { - BMSC-CAR cells express CXCL12- maintenance and } \\
\text { quiescence HSC. } \\
\text { - Macrophage- modulate CXCL12 pathway. } \\
\text { - Monocytes- regulate osteoblasts, promote } \\
\text { pro-inflammatory cytokine environment. }\end{array}$ & $\begin{array}{l}\text { - Alteration CXCL12 pathway: upregulated in JAk2+ endothelial } \\
\text { cells, downregulated BMSC- promotes expansion mutated } \\
\text { HSC. } \\
\text { - Clonal endothelial cells support neo-angiogenesis by } \\
\text { VEGF production. } \\
\text { - Increase survival mutated HSC. } \\
\text { - Alteration of HIF-1 } \alpha \text { and hypoxia status. } \\
\text { - BMSC promote expansion of osteoblasts by cell contact and } \\
\text { excessive TGF } \beta 1 \text {, Notch and cytokines. } \\
\text { - Overproduction of inflammatory markers produce } \\
\text { fibrosis. }\end{array}$ \\
\hline Sympathetic nervous system & $\begin{array}{l}\text { - Noradrenaline secretion regulate HSC circulation } \\
\text { and functionality. }\end{array}$ & $\begin{array}{l}\text { - Local neuropathy by reduced expression of } \mathrm{Nestin}^{+} \text {and } \\
\text { CXCL12 promoting HSC expansion. }\end{array}$ \\
\hline Extracellular matrix & $\begin{array}{l}\text { - Integrity, proliferation and elasticity of BMN. } \\
\text { - Presence of growth factors (TGFß-1, PEGF, VEGF) } \\
\text { to maintain HSC. }\end{array}$ & $\begin{array}{l}\text { - Increase cytokines and growth factor levels (TGF } \beta-1 \text {, } \\
\text { PEGF, VEGF) promotes fibrogenesis. } \\
\text { - VEGF contributes to MK maturation and migration. } \\
\text { - Decrease of MMP and increase of LOX favoring fibrosis. }\end{array}$ \\
\hline
\end{tabular}

SNO: spindle-shaped N-cadherin ${ }^{+}$osteoblasts; HSC: hematopoietic stem cells; BMSC: bone marrow mesenchymal cells; VEGF: vascular endothelial growth factor; PDG: platelet-derived growth factor; TGF $\beta 1$ : transforming growth factor beta; HIF-1 $\alpha$ : Hypoxia inducible factor 1-alpha; MK: megakaryocytes; MMP: matrix metalloproteinases; LOX: Lysyl Oxidase. 
Table 2. Therapies targeting directly or indirectly the bone marrow niche.

\begin{tabular}{|c|c|c|c|c|}
\hline Drug & Target & Disease/update results & Reference & \\
\hline PACRITINIB & JAK2/FLT3 inhibitor & $\begin{array}{l}\text { MF with thrombocytopenia } \\
\text { Spleen responses } 18 \% \text { volume reduction } \geq 35 \% \text { - } \\
\text { PERSIST I \& II trials }\end{array}$ & $\begin{array}{l}82 \\
83\end{array}$ & Clinical trials ongoing \\
\hline MOMELOTINIB & JAK1/2 inhibitor & $\begin{array}{l}\text { MF } \\
\text { Anemia and transfusion responses in addition to } \\
\text { spleen and symptoms: } \\
\text { - SIMPLIFY } 1 \text { (momelotinib vs ruxolitinib): } \\
\text { 66.5.\% transfusion independent at week } 24 \text {. } \\
\text { 26.5\% reduction of spleen volume } \geq 35 \% \\
\text { - SIMPLIFY } 2 \text { (momelotinib vs BAT): } 7 \% \text { spleen } \\
\text { volume } \geq 35 \%\end{array}$ & 85 & $\begin{array}{l}\text { Planned MOMENTUM } \\
\text { Study }\end{array}$ \\
\hline FEDRATINIB & Selective JAK 2 inhibitor & $\begin{array}{l}\text { MF (ruxolitinib resistant or intolerant) } \\
\text { Spleen response and symptoms improvement. } \\
\text { - JAKARTA-1: reduction spleen volume } \geq 35 \%, 36 \% \text { (400mg) } \\
\text { and 40\% (500-mg compared with placebo. } \\
\text { - JAKARTA- } 2 \text { : Second line study } 55 \% \text { of patients achieved } \\
\text { spleen volume } \geq 35 \% \text {. }\end{array}$ & 86 & $\begin{array}{l}\text { Clinical trials ongoing/ } \\
\text { planned }\end{array}$ \\
\hline
\end{tabular}

Recent hold due to Wernicke's encephalopathy removed.

Approved by FDA in 2019.Fibrosis grade-reduction in 44\%

(8/18) patients after cycle 6 .

\begin{tabular}{|c|c|c|c|c|}
\hline NAVITOCLAX & BCL-2 inhibitor & $\begin{array}{l}\text { MF failed ruxolitinib. } \\
\text { Clinical trial ongoing in combination with ruxolitinib }\end{array}$ & $\begin{array}{l}\text { No data } \\
\text { published } \\
\text { available yet }\end{array}$ & Clinical trial ongoing \\
\hline PANOBINOSTAT & $\begin{array}{l}\text { Histone deacetylase } \\
\text { inhibitor }\end{array}$ & $\begin{array}{l}\text { MF -combination with ruxolitinib } \\
36 \% \text { achieved overall response by IWG-MRT } \\
\text { Median spleen reduction was } 34 \% \\
6.8 \% \text { decrease in JAK2 allele burden }\end{array}$ & 119 & $\begin{array}{l}\text { Clinical trial ongoing - } \\
\text { expansion phase. }\end{array}$ \\
\hline IMETELSTAT & Telomerase inhibitor & $\begin{array}{l}\text { MF and ET. } \\
\text { - MF clinical trial: Pilot- } 33 \text { MF patients- complete and } \\
\text { partial response } 7(21 \%) \text { median response } 18 \mathrm{~m} \text {. } \\
\text { Bone marrow fibrosis reversal in } 4 \text { with CR. } \\
\text { Molecular response } 3 \text { / } 4 \text { patients. } \\
\text { - Phase-II study: OS } 19.9 \text { months in low dose and } \\
29.9 \text { months in higher dose. } 93 \% \text { patients discontinued } \\
\text { study (25\% due to adverse events). } \\
\text { Update data compared with real world showed OS } \\
\text { was } 30.69 \text { months. Significant myelosuppression and } \\
\text { hepatic toxicity in some. } \\
\text { ET clinical trial: } 16 / 18 \text { (89\%) achieve complete } \\
\text { hematological response. And 7/8 molecular response } \\
\text { with allele burden reduction between } 15-66 \% \text {. } \\
\text { Bone marrow fibrosis reduction of at least } 1 \text { grade } \\
\text { was described in 4/6 (67\%) }\end{array}$ & 94 & Recruitment suspended \\
\hline IDASANUTLIN & MDM2 inhibitor & $\begin{array}{l}\text { PV, ET and MF } \\
\text { Alters the MDM2/p53 interaction. } \\
\text { PV/ET clinical trial: } 58 \% \text { response on monotherapy } \\
\text { and } 50 \% \text { for combined therapy after } 6 \text { cycles. } \\
\text { Combined with BET inhibitor in MF: Reduction } \\
\text { of hematopoietic colony formation CD34+ in MF. } \\
\text { Reduction in pro-inflammatory cytokines (decreased } \\
\text { the levels of IL- } 8 \text { in MF MNC by 50\% }(P=0.0003))\end{array}$ & 96 & Clinical trial ongoing \\
\hline BET inhibitor & & $\begin{array}{l}\text { Combined with ruxolitinib in MF } \\
\text { MF- inhibition of the NF-KB pathway, reduction } \\
\text { of inflammatory cytokines. Reduction of bone marrow fibrosis. }\end{array}$ & S. & Clinical trial ongoing \\
\hline
\end{tabular}




\begin{tabular}{|c|c|c|c|c|}
\hline \multirow[t]{2}{*}{ RUXOLITINIB } & JAK inhibitor & $\mathrm{MF}$ & 69,97 & $\begin{array}{l}\text { Single agent studies } \\
\text { closed }\end{array}$ \\
\hline & & $\begin{array}{l}\text { Association between reduction in fibrosis grade } \\
\text { and cytokines reduction }(\mathrm{AUC}=0.85939, P=0.0134)\end{array}$ & & \\
\hline TAMOXIFEN & Estrogen receptor antagonist & $\begin{array}{l}\text { MPN } \\
\text { Reduction of JAK2 and CALR allele burden } \geq 50 \% \text { at } \\
24 \text { weeks mutation }\end{array}$ & $\begin{array}{l}\text { No data } \\
\text { published } \\
\text { as yet. }\end{array}$ & Clinical trial ongoing \\
\hline PRM-151 & $\begin{array}{l}\text { Recombinant human } \\
\text { pentraxin-2 analogue }\end{array}$ & $\begin{array}{l}\text { MF } \\
\text { Fibrosis grade reduced in } 25 \text { patients by } \geq 1 \text { initial study. } \\
\text { In extension phase, improvements in } 71 \% \text { and } 44 \% \text { of } \\
\text { individuals with grade } 2 \& 3 \text { fibrosis at baseline. } \\
\text { Updated results showed } 28 \% \text { decrease in fibrosis. }\end{array}$ & $\begin{array}{l}100 \\
101 \\
102\end{array}$ & Study closed \\
\hline IPI926 & Hedgehog inhibitor & $\begin{array}{l}\text { MF } \\
\text { No improvements in fibrosis }\end{array}$ & 103,104 & Study discontinued \\
\hline $\begin{array}{l}\text { SONIDEGIB (LDE225, } \\
\text { NOVARTIS, } \\
\text { SWITZERLAND) }\end{array}$ & SMO receptor antagonist & $\begin{array}{l}\text { MF in combination with ruxolitinib } \\
\text { Spleen and symptoms responses- } 65 \% \text { of pts achieved } \\
a \geq 50 \% \text { reduction spleen and } 9 \text { pts had resolution } \\
\text { of splenomegaly. } \\
\text { Reduction of bone marrow fibrosis }\end{array}$ & 105 & - \\
\hline PIRFENIDONE & Antifibrotic agent & $\begin{array}{l}\text { MF } \\
\text { In vitro- reduced both fibroblast activity and ECM } \\
\text { components } \\
\text { In vivo- minimal clinical benefits. }\end{array}$ & 106 & - \\
\hline FRESOLIMUMAB & $\begin{array}{l}\text { Monoclonal antibody } \\
\text { against TGF- } \beta\end{array}$ & $\begin{array}{l}\text { MF } \\
\text { No relevant changes in fibrosis }\end{array}$ & 107 & Clinical trial ongoing \\
\hline
\end{tabular}

\begin{tabular}{lll}
$\begin{array}{l}\text { GALUNISERTIB } \\
(\text { LY2157299) }\end{array}$ & TGF- $\beta$ receptor I kinase & $\begin{array}{l}\text { MF } \\
\text { Reductions in fibrosis in murine models }(P=0.02)\end{array}$ \\
\hline SIMTUZUMAB & $\begin{array}{l}\text { Monoclonal antibodies } \\
\text { against the Lysyl oxidase like-2 }\end{array}$ & MF- monotherapy and combination with Ruxolitinib
\end{tabular}

Reduced fibrosis score at 24 weeks in 36.7\%.

Overall limited efficacy

\begin{tabular}{ll} 
AZACITIDINE & Hypomethylating agents \\
DECITABINE & \\
\hline MIRABEGRON & Oral $\beta-3$ adrenergic agonist
\end{tabular}

MF- high risk and accelerated/blastic phase. Combined with ruxolitinib- 57\% fibrosis reduction and spleen responses observed.

MF-Blastic phase

Increased OS.

\section{MPN- JAK2 V617F positive}

Increase in Nestin ${ }^{+}$BMSC (week 24 was $3.52 / \mathrm{mm}^{2}$

[95\%CI: 1.65-5.39])

Mild reduction in fibrosis 1.0 (interquartile range $0-3$ )

to 0.5 (interquartile range $0-2)(P=0.01)$ )

Modulation of megakaryocyte clustering

\begin{tabular}{lll} 
BEVACIZUMAB & Anti-VEGF agent & MPN \\
& No significant benefit \\
\hline VATALANIB & Anti-VEGF receptors & MF \\
& & $3 \%$ CR and $17 \%$ clinical improvement \\
& $3 / 7$ patients have bone marrow fibrosis reduction \\
BORTEZOMIB & Proteasome inhibitor & MF \\
& indirectly inhibits HIF1- $\alpha$ & $9 / 15$ patients reduced in the bone marrow vessel density. \\
MF: myelofibrosis; CR: complete response; OS: overall survival; PV: polycythemia vera; ET: essential thrombocythaemia; MPN: myeloproliferative neoplasm; CI: confidence interval; MNC: \\
mononuclear cells; BMSC: bone marrow mesenchymal stem cells; VEGF: vascular endothelial growth factor; HIF1- $\alpha$ : hypoxia-inducible factor.
\end{tabular}

patients, either JAKi naive or those with resistance or intolerance to ruxolitinib in terms of spleen response and improvement of symptoms ${ }^{86,87}$ The FDA placed the drug on hold due to several cases of Wernicke's encephalopathy, but after further investigations, this clinical hold has now been removed and the agent has recently been approved by the FDA in both the first-line and successive treatment settings in $\mathrm{MF}^{88}$
Multiple alternative pathways are being investigated as potential therapeutic targets for MPN patients; ongoing trials are investigating the use of BET inhibitors, PI3K inhibitors, HDAC inhibitors, BCL-2 inhibitors and MDM2 inhibitors, to name only a few (Table 2). BCL-2 protein inhibitors (BH3-mimetics) have already been investigated in lymphoid and other myeloid disorders. ${ }^{99}$ Curiously, these agents trigger remarkable megakaryocytic and 
mature platelet apoptosis. ${ }^{90}$ A phase II clinical trial of the BCL-2 inhibitor navitoclax in combination with ruxolitinib in MF patients is ongoing and results are awaited with interest. Other emerging agents indirectly targeting the marrow niche are the telomerase inhibitor, imetelstat (GRN163L, Geron, USA), which has been investigated in both ET and MF patients and initial clinical results are encouraging. ${ }^{91,92}$ Unfortunately, subsequent studies in $\mathrm{MF}$ revealed limited overall spleen responses, significant myelosuppression, and in some patients, hepatic toxicity; therefore, recruitment for the study was suspended (Geron Corporation, June 7 2017, press release). However, the data presented in ASH-2018 showed complete and partial responses in $21 \%$ cases, with bone marrow fibrosis reversal in four cases with complete response (CR); OS after 27.4 months of treatment was 19.9 months in the low-dose therapy arm and 29.9 months in the higher-dose therapy arm. ${ }^{93}$ Unfortunately, $93 \%$ of patients discontinued the study, and of these, $25 \%$ were due to adverse events. Recent data presented at the EHA congress 2019 demonstrated that when survival data from the $9.4 \mathrm{mg} / \mathrm{kg}$ imetelstat-cohort, from the phase-II trial in ruxolitinib relapsed/refractory higher-risk $M F$, was compared to 'real world' data for this group of patients treated with best alternative therapy (BAT), there was a potential OS advantage (30.69 months in the imetelstat group, HR 0.35 months, $P<0019)$; although this was an unweighted analysis and had inherent comparative limitations. ${ }^{94}$ Geron plans to conduct an up-dated phase II trial meeting with the FDA to determine if there is a regulatory path forward for imetelstat in MF in 2020.

MDM2 inhibitors alter the MDM2/p53 interaction, in order to restore p53 functionality/activity. Preliminary data from early phase studies in PV and ET demonstrated favorable clinical responses. Mascarenhas et al. recently presented the results of a phase I study in which 13 JAK2mutated PV/ET patients were treated with idasanutlin and combined with pegylated interferon if a partial response was not achieved following cycle 6. Responses were robust: $58 \%$ for the monotherapy cohort and $50 \%$ for the combination therapy cohort after 6 cycles, with a median treatment duration of 16.8 months. ${ }^{95}$ Two multinational clinical trials are currently open investigating the efficacy and safety of the MDM2 inhibitor KRT-232 for ruxolitinib-failure/intolerant MF patients and poorly controlled PV patients. Recently, Lu et al. presented early data from a combinatorial study of an MDM2 antagonist and BET inhibitor in MF patients. ${ }^{96}$ This combination reduced hematopoietic colony formation by MF-CD34+ cells and targets the microenvironment by reducing the pro-inflammatory cytokine milieu. Results of this particular combinatorial approach are eagerly awaited, as is the combination of a BET inhibitor with JAKi. Lastly, as introduced above, another potential niche pathway target is the estrogen-signaling axis. Inhibition of estrogen-signaling has recently been explored in the TAMARIN trial, investigating clinical benefits and molecular responses induced by the concomitant administration of tamoxifen to patients with MPN established on treatment (excluding interferon).

Historically, the exact relationship between BM fibrosis and clinical outcome/prognosis in MF has been somewhat unclear. An important question is: does improvement in BM fibrosis correlate with improved overall symptom/ spleen burden and OS? This has not been comprehensive- ly studied in the clinical trial setting, particularly in the longer term. Kvasnicka et al. recently examined the effects of long-term ruxolitinib therapy on BM cytomorphology and fibrosis in 68 patients compared to 192 matching patients with BAT. ${ }^{97}$ Compared to baseline reticulin fibrosis grade, ruxolitinib, in contrast to BAT, was associated with augmented odds of fibrosis grade stabilization or improvement and decreased odds of a worsening of reticulin fibrosis. Furthermore, this was often associated with higher degrees of reduction in spleen size. Similar effects have also been noted in a much smaller cohort of patients treated with fedratinib. ${ }^{98,99}$ Collectively, these data suggest a possible disease-modifying effect, at least in a subset of those patients undergoing JAKi therapy, which evidently requires a longer duration of drug exposure. Novel therapies such as PRM151, a recombinant human pentraxin-2 analog, have also demonstrated promising findings following reductions in BM fibrosis in some patients with $\mathrm{MF}$. In the first stage of the clinical trial, 27 patients with either primary or secondary MF and $\geq$ grade 2 reticulin fibrosis were due to receive PRM-151 \pm ruxolitinib for 24 weeks; 20 completed therapy. ${ }^{100}$ In general, the agent was well tolerated, both alone and with JAKi, with no evidence of myelosuppression. Improvements in symptoms and modest reductions in splenomegaly in some were observed and 11 out of 25 patients evaluated had a reduction in BM fibrosis by $\geq 1$ grade. A total of 18 patients were in the open label extension, all of whom received a monthly infusion of PRM-151 at $10 \mathrm{mg} / \mathrm{kg}$, treated for up to 35 cycles (140 weeks). ${ }^{101}$ A total of $50 \%$ were also receiving ruxolitinib. A similar percentage of patients experiencing reductions in spleen size and improvements in total symptom score (TSS) were seen in both the combination and monotherapy arms. Improvements in reticulin grade was observed in $71 \%$ and $44 \%$ of those with Grade 2 and 3 marrow fibrosis at baseline, respectively. Recent results presented at the EHA 2019 by Verstovsek et al. showed that BM fibrosis decreased at any time point in $28 \%$ of patients, and $16-29 \%$ patients had a $\geq 50 \%$ reduction in transfusion requirement or hemoglobin improved $>10 \mathrm{~g} / \mathrm{L}$ for 12 consecutive weeks. ${ }^{102}$

Other therapeutic agents have been developed during recent years to specifically target the BM fibrosis and/or relevant pathways in MPN, but with limited success. Inhibitors of hedgehog signaling, important in both primitive and definitive hematopoiesis, cellular proliferation and survival, have been studied both as monotherapies and in combination with ruxolitinib in MF. ${ }^{103}$ IPI926, an oral hedgehog-inhibitor, was studied as a monotherapy in MF; however, no significant improvements in fibrosis were reported and the study was discontinued. ${ }^{104}$ The SMO-inhibitor sonidegib (LDE225, Novartis, Switzerland) has been investigated in combination with ruxolitinib in a phase-Ib/II study and demonstrated spleen and symptom responses in a minority of patients, and, in some patients, reductions or stability in BM fibrosis. ${ }^{105}$ Schneider et al. have showed that Gli1 ${ }^{+}$mesenchymal cells are involved in the fibrosis pathogenesis of MF. The investigators have used GANT61, an inhibitor of Gli1 transcription factor that regulates the hedgehog signaling pathway, in MF murine models and demonstrated reductions in both the fibrosis and the malignant clone. These results suggest a possible new target in reducing marrow fibrosis in MF.58

Pirfenidone, an established antifibrotic agent, showed promising results in vitro by reducing both fibroblast activ- 
ity and ECM components; however, a phase-II study in MF failed to show significant clinical benefits. ${ }^{106}$ A study with a monoclonal antibody against TGF- $\beta$ (fresolimum$\mathrm{ab}$ ) is currently ongoing in MF, although preliminary results have not described any relevant changes in fibrosis. ${ }^{107}$ Finally, an inhibitor of the TGF- $\beta$ receptor-Ikinase, galunisertib (LY2157299) has been shown to induce reductions in fibrosis in MPN murine models. ${ }^{108}$ Monoclonal antibodies against LOL-2 (simtuzumab) have been tested either as monotherapy or in combination with ruxolitinib in a phase-II study with overall limited efficacy in $\mathrm{MF}^{109}$ despite the promising in vitro results. Hypomethylating agents such as azacitidine (5-Aza) and decitabine have been investigated in high-risk MF patients and accelerated/blastic phases of the disease. A combined clinical trial with ruxolitinib and 5-Aza is currently ongoing and recent published results have demonstrated marrow fibrosis reductions in $57 \%$ of the total cohort (31 cases) at 24 months in addition to acceptable spleen responses. ${ }^{110}$ Further research is required to determinate the impact of these hypomethylating agents, with particular attention to the MPN marrow niche.

Therapeutic modulation of the neuro-HSC niche in $M P N$, introduced above, has recently been explored. Drexler et al. report on a phase II trial of an oral $\beta-3$ adrenergic agonist (mirabegron) in 39 patients, many of whom had a long duration of disease, with a JAK2 V617F-mutated MPN who underwent treatment for up to six months. BM core analysis in 20 of the enrolled patients showed increases in Nestin ${ }^{+}$BMSC in a proportion of patients (but not in those also receiving hydroxycarbamide); several showed mild reductions in fibrosis and modulation of the characteristic megakaryocyte clustering. ${ }^{11,112}$ Although the study end points of a $>50 \%$ reduction in $J A K 2$ allelic burden or sustained reductions in splenomegaly were not reached, these intriguing data highlight the potential therapeutic avenues of targeting this neuro-HSC axis in MPN.

With regard to aberrant upregulation of cytokines in $\mathrm{MPN}$, ruxolitinib and other JAKi have been shown to decrease levels of many pro-inflammatory cytokines, including both VEGF and PDGF, as discussed above. ${ }^{69}$ The Myeloproliferative Disorders Research Consortium conducted a phase II trial of the anti-VEGF agent (bevacizum$\mathrm{ab}$ ) in 13 patients, 11 of whom were evaluable, to assess if a potential disease modification could be achieved. The dosing strategy was $15 \mathrm{mg} / \mathrm{kg}$ intravenously every 21 days; none of the patients demonstrated significant benefits. This lack of response coupled with toxicity led to the premature closure of the study; the authors commented that different dosing strategies may be required. ${ }^{113}$ Other drugs have been developed to target VEGF-receptors, like the tyrosine kinase inhibitor vatalanib, but with modest results. ${ }^{114}$ Lastly, control or regulation of the marrow hypoxia status could be a potential goal in the management of MPN in view of the key role of oxygen regulation pathways in the pathogenesis and maintenance of these disorders. HIF-1 $\alpha$ is essential for HSC maintenance, as discussed. However, in the MPN environment, it participates in both angiogenesis and promotion of suppressor genes, aiding clonal cell adaptation to a hypoxic environment. ${ }^{115,116}$ Therefore, targeting HIF1- $\alpha$ has been explored in recent years in both solid and non-solid cancers. ${ }^{117}$ Bortezomib, a proteasome inhibitor extensively used in plasma cell dyscrasias, indirectly inhibits HIF- $1 \alpha$ in MF patients as demonstrated by Barosi et al. ${ }^{118}$ Although, to date, few published studies have focused on targeting hypoxia and HIF-pathways in MPN, it remains an attractive area of research.

\section{Conclusions}

As our knowledge expands, the complex and dynamic structure of the bone marrow niche in both health and disease is being constantly refined. It is apparent that, in MPN, the mutated-HSC disrupts the harmony of the bone marrow niche, promoting a self-reinforcing environment that facilities their proliferation at the expense of normal hematopoiesis. Furthermore, the MPN-niche can confer therapeutic resistance and potentiate disease progression towards blastic phase disease. Besides the potentially curative procedure of allogeneic stem cell transplantation, attempts to target various components of the MPN-niche have led to variable results and often a lack of sustained clinical benefit. Given the complexity, it is, therefore, increasingly apparent that combinatorial or sequenced therapeutic strategies will be required. As our appraisal of niche dysregulation grows, and we learn more from the current therapeutic trials discussed above, more rational niche-targeted treatment strategies will ultimately be developed.

\section{References}

1. Arber DA, Orazi A, Hasserjian R, et al. The 2016 revision to the World Health Organization classification of myeloid neoplasms and acute leukemia. Blood. 2016;127(20):2391-2406.

2. Moulard O, Mehta J, Fryzek J, Olivares R, Iqbal U, Mesa RA. Epidemiology of myelofibrosis, essential thrombocythemia, and polycythemia vera in the European Union. Eur J Haematol. 2014;92(4):289-297.

3. Szuber N, Vallapureddy RR, Penna D, et al. Myeloproliferative neoplasms in the young: Mayo Clinic experience with 361 patients age 40 years or younger. Am J Hematol.
2018;93(12):1474-1484.

4. Yogarajah M, Tefferi A. Leukemic Transformation in Myeloproliferative Neoplasms: A Literature Review on Risk, Characteristics, and Outcome. Mayo Clin Proc. 2017;92(7):1118-1128.

5. James C, Ugo V, Le Couédic JP, et al. A unique clonal JAK2 mutation leading to constitutive signalling causes polycythaemia vera. Nature. 2005;434(7037):1144-1148.

6. Levine RL, Wadleigh M, Cools J, et al. Activating mutation in the tyrosine kinase JAK2 in polycythemia vera, essential thrombocythemia, and myeloid metaplasia with myelofibrosis. Cancer Cell. 2005;7(4):387397.

7. Kralovics R, Passamonti F, Buser AS, et al. A gain-of-function mutation of JAK2 in myelo- proliferative disorders. $N$ Engl J Med. 2005;352(17):1779-1790.

8. Baxter EJ, Scott LM, Campbell PJ, et al. Acquired mutation of the tyrosine kinase JAK2 in human myeloproliferative disorders. Lancet. 2005;365(9464):1054-1061.

9. Vainchenker W, Constantinescu SN, Plo I. Recent advances in understanding myelofibrosis and essential thrombocythemia F1000Res. 2016;5.

10. Nangalia J, Massie CE, Baxter EJ, et al. Somatic CALR Mutations in Myeloproliferative Neoplasms with Nonmutated JAK2. N Engl J Med. 2013;369(25):2391-2405.

11. Klampfl T, Gisslinger $\mathrm{H}$, Harutyunyan AS, et al. Somatic Mutations of Calreticulin in Myeloproliferative Neoplasms. N Engl J 
Med. 2013:369(25):2379-2390

12. Rumi E, Cazzola M. Diagnosis, riskstratification, and response evaluation in classical myeloproliferative neoplasms. Blood. 2017;129(6):680-693.

13. Shirane S, Araki M, Morishita S, et al. JAK2, CALR, and MPL mutation spectrum in Japanese patients with myeloproliferative neoplasms. Haematologica. 2015;100(2): e46-e48.

14. Ferreira Cristina S, Polo B, Lacerda JF. Somatic Mutations in Philadelphia Chromosome-Negative Myeloproliferative Neoplasms. Semin Hematol. 2018;55(4): 215-222.

15. Nangalia J, Green AR. Myeloproliferative neoplasms: from origins to outcomes. Blood. 2017;130(23):2475-2483.

16. Lord BI, Testa NG, Hendry JH. The relative spatial distributions of CFUs and CFUc in the normal mouse femur. Blood. 1975;46(1): 65-72.

17. Schofield R. The relationship between the spleen colony-forming cell and the haemopoietic stem cell. Blood Cells. 1978;4 (1-2):7-25.

18. Sugiyama $T$, Nagasawa $T$. Bone marrow niches for hematopoietic stem cells and immune cells. Inflamm Allergy Drug Targets. 2012;11(3):201-206.

19. Colaianni G, Sun L, Di Benedetto A, et al. Bone marrow oxytocin mediates the anabolic action of estrogen on the skeleton. J Biol Chem. 2012;287(34):29159-29167.

20. Nilsson SK, Johnston HM, Coverdale JA. Spatial localization of transplanted hemopoietic stem cells: inferences for the localization of stem cell niches. Blood. 2001;97(8): 2293-2299.

21. Lo Celso C, Fleming HE, Wu JW, et al. Liveanimal tracking of individual haematopoietic stem/progenitor cells in their niche. Nature. 2009:457(7225):92-96.

22. Xie Y, Yin T, Wiegraebe W, et al. Detection of functional haematopoietic stem cell niche using real-time imaging. Nature. 2009;457 (7225):97-101.

23. Taichman RS. Blood and bone: Two tissues whose fates are intertwined to create the hematopoietic stem-cell niche. Blood. 2005;105(7):2631-2639.

24. Taichman RS, Emerson SG. Human osteoblasts support hematopoiesis through the production of granulocyte colony-stimulating factor. J Exp Med. 1994;179(5):16771682.

25. Taichman RS, Reilly MJ, Verma RS, et al. Augmented production of interleukin- 6 by normal human osteoblasts in response to CD34+ hematopoietic bone marrow cells in vitro. Blood. 1997:89(4):1165-1172.

26. Galán-Díez M, Kousteni S. A bone marrow niche-derived molecular switch between osteogenesis and hematopoiesis. Genes Dev. 2018;32(5-6):324-326.

27. Calvi LM, Adams GB, Weibrecht KW, et al. Osteoblastic cells regulate the haematopoietic stem cell niche. Nature. 2003;425(6960): 841-846.

28. Zhang J, Niu C, Ye L, et al. Identification of the haematopoietic stem cell niche and control of the niche size. Nature. 2003;425 (6960):836-841.

29. Askmyr M, Sims NA, Martin TJ, Purton LE. What is the true nature of the osteoblastic hematopoietic stem cell niche? Trends Endocrinol Metab. 2009;20(6):303-309.

30. Méndez-Ferrer S, Lucas D, Battista M, Frenette PS. Haematopoietic stem cell release is regulated by circadian oscillations. Nature. 2008;452(7186):442-447.
31. Schmitt-Graeff AH, Nitschke R, Zeiser R The hematopoietic niche in myeloproliferative neoplasms. Mediators Inflamm. 2015;2015:347270.

32. Yu VWC, Saez B, Cook C, et al. Specific bone cells produce DLL4 to generate thymus-seeding progenitors from bone marrow. J Exp Med. 2015;212(5):759-774.

33. Miyamoto T. Role of osteoclasts in regulating hematopoietic stem and progenitor cells. World J Orthop. 2013;4(4):198-206.

34. Kollet O, Dar A, Lapidot T. The Multiple Roles of Osteoclasts in Host Defense: Bone Remodeling and Hematopoietic Stem Cell Mobilization. Annu Rev Immunol. 2007:25:51-69.

35. Mansour A, Abou-Ezzi G, Sitnicka E, W Jacobsen SE, Wakkach A, Blin-Wakkach C. Osteoclasts promote the formation of hematopoietic stem cell niches in the bone marrow. J Exp Med. 2012;209(3):537-549.

36. Miyamoto T. Regulators of osteoclast differentiation and cell-cell fusion. Keio J Med. 2011;60(4):101-105

37. Li H, Hong S, Qian J, Zheng Y, Yang J, Yi O. Cross talk between the bone and immune systems: osteoclasts function as antigen-presenting cells and activate CD4+ and CD8+ cells. Blood. 2010;116(2):210-217

38. Kobayashi H, Butler JM, O'Donnell R, et al Angiocrine factors from Akt-activated endothelial cells balance self-renewal and differentiation of haematopoietic stem cells. Nat Cell Biol. 2010;12(11):1046-1056.

39. Winkler IG, Barbier V, Nowlan B, et al. Vascular niche E-selectin regulates hematopoietic stem cell dormancy, self renewal and chemoresistance. Nat Med. 2012;18(11):1651-1657.

40. Kunisaki Y, Bruns I, Scheiermann C, et al. Arteriolar niches maintain haematopoietic stem cell quiescence. Nature. 2013;502 (7473):637-643

41. Nombela-Arrieta C, Pivarnik G, Winkel B, et al. Quantitative imaging of haematopoietic stem and progenitor cell localization and hypoxic status in the bone marrow microenvironment. Nat Cell Biol. 2013;15(5):533543.

42. Boulais P, Frenette P. Making sense of hematopoietic stem cell niches. Blood. 2015;125(17):2621-2630.

43. García-García A, de Castillejo CLF, MéndezFerrer S. BMSCs and hematopoiesis. Immunol Lett. 2015;168(2):129-135.

44. Méndez-Ferrer S, Chow A, Merad M, Frenette PS. Circadian rhythms influence hematopoietic stem cells. Curr Opin Hematol. 2009;16(4):235-242.

45. Gattazzo F, Urciuolo A, Bonaldo P. Extracellular matrix: A dynamic microenvironment for stem cell niche. Biochim Biophys Acta. 2014;1840(8):2506-2519.

46. Mead AJ, Mullally A. Myeloproliferative neoplasm stem cells. Blood. 2017;129(12): 1607-1616.

47. Mullally A, Poveromo L, Schneider RK, AlShahrour F, Lane SW, Ebert BL. Distinct roles for long-term hematopoietic stem cells and erythroid precursor cells in a murine model of Jak2V617F-mediated polycythemia vera. Blood. 2012;120(1):166-172

48. Lundberg P, Takizawa H, Kubovcakova L, et al. Myeloproliferative neoplasms can be initiated from a single hematopoietic stem cell expressing JAK2-V617F. J Exp Med. 2014;211(11):2213-2230.

49. Chen E, Schneider RK, Breyfogle LJ, et al. Distinct effects of concomitant Jak2V617F expression and Tet2 loss in mice promote disease progression in myeloproliferative neoplasms. Blood. 2015;125(2):327-335

50. Schepers K, Pietras EM, Reynaud D, et al. Myeloproliferative neoplasia remodels the endosteal bone marrow niche into a selfreinforcing leukemic niche. Cell Stem Cell 2013;13(3):285-299.

51. Kollet O, Vagima Y, D'Uva G, et al Physiologic corticosterone oscillations regulate murine hematopoietic stem/progenitor cell proliferation and CXCL12 expression by bone marrow stromal progenitors. Leukemia. 2013;27(10):2006-2015.

52. Iwasaki H, Suda T. Hematopoietic stem cells and their niche. Cancer Science. 2009;100 (7):1166-1172.

53. Spanoudakis E, Papoutselis M, Bazdiara I et al. The JAK2V617F point mutation increases the osteoclast forming ability of monocytes in patients with chronic myeloproliferative neoplasms and makes their osteoclasts more susceptible to JAK2 inhibition. Mediterr I Hematol Infect Dis. 2018;10(1):e2018058

54. Korn C, Méndez-Ferrer S. Myeloid malignancies and the microenvironment. Blood. 2017;129(7):811-822.

55. Mitsumori T, Nozaki Y, Kawashima I, et al. Hypoxia inhibits JAK2V617F activation via suppression of SHP-2 function in myeloproliferative neoplasm cells. Exp Hematol. 2014;42(9):783-792.

56. Velasco-Hernandez T, Tornero D, Cammenga J. Loss of HIF- $1 \alpha$ accelerates murine FLT-3 ITD-induced myeloproliferative neoplasia. Leukemia. 2015;29(12):23662374.

57. Schepers K, Campbell TB, Passegue E. Normal and Leukemic Stem Cell Niches: Insights and Therapeutic Opportunities. Cell Stem Cell. 2015;16(3):254-267.

58. Schneider RK, Mullally A, Dugourd A, et al. Gli1(+) Mesenchymal Stromal Cells Are a Key Driver of Bone Marrow Fibrosis and an Important Cellular Therapeutic Target. Cell Stem Cell. 2017;20(6):785-800.e8.

59. Ramos TL, Sánchez-Abarca LI, Rosón-Burgo $\mathrm{B}$, et al. Mesenchymal stromal cells (MSC) from JAK2+ myeloproliferative neoplasms differ from normal MSC and contribute to the maintenance of neoplastic hematopoiesis. PLoS One. 2017;12(8): e0182470.

60. Arai F, Hirao A, Ohmura $M$, et al Tie2/angiopoietin-1 signaling regulates hematopoietic stem cell quiescence in the bone marrow niche. Cell. 2004;118(2):149161.

61. Arranz L, Sánchez-Aguilera A, Martín-Pérez $D$, et al. Neuropathy of haematopoietic stem cell niche is essential for myeloproliferative neoplasms. Nature. 2014;512(7512):7881

62. Sánchez-Aguilera A, Arranz L, Martín-Pérez $\mathrm{D}$, et al. Estrogen Signaling Selectively Induces Apoptosis of Hematopoietic Progenitors and Myeloid Neoplasms without Harming Steady-State Hematopoiesis. Cell Stem Cell. 2014;15(6):791-804.

63. Vannucchi AM, Bianchi L, Paoletti F, et al. A pathobiologic pathway linking thrombopoietin, GATA-1, and TGF- $\beta 1$ in the development of myelofibrosis. Blood. 2005;105(9): 3493-3501.

64. Leiva O, Ng SK, Chitalia S, Balduini A, Matsuura S, Ravid K. The role of the extracellular matrix in primary myelofibrosis. Blood Cancer J. 2017;7(2):1-9.

65. Wang JC, Novetsky A, Chen C, Novetsky AD. Plasma matrix metalloproteinase and tissue inhibitor of metalloproteinase in patients with agnogenic myeloid metaplasia 
BM niche dysregulation in MPN

or idiopathic primary myelofibrosis. $\mathrm{Br} J$ Haematol. 2002;119(3):709-712.

66. Lu GM, Chang LJ, Pu JZ, et al. Regulation of Ruxolitinib on matrix metalloproteinase in JAK2V617F positive myeloroliferative neoplasms cells. Zhonghua Xe Ye Xe Zn Zhi. 2017;38(2):140-145.

67. Tadmor T, Bejar J, Attias D, et al. The expression of lysyl-oxidase gene family members in myeloproliferative neoplasms. Am J Hematol. 2013;88(5):355-358.

68. McLornan DP, Yakoub-Agha I, Robin M, Chalandon Y, Harrison CN, Kroger N. Stateof-the-art review: allogeneic stem cell transplantation for myelofibrosis in 2019. Haematological. 2019;104(4):659-668.

69. Verstovsek S, Mesa RA, Gotlib J, et al. Longterm treatment with ruxolitinib for patients with myelofibrosis: 5-year update from the randomized, double-blind, placebo-controlled, phase 3 COMFORT-I trial. J Hematol Oncol. 2017;10(1):1-14.

70. Harrison CN, Vannucchi AM, Kiladjian JJ, et al. Long-term efficacy and safety in comfortII, a phase 3 study comparing ruxolitinib with best available therapy for the treatment of myelofibrosis: 5-year final study results. Blood. 2015;126(23):59.

71. Verstovsek S, Vannucchi AM, Griesshammer $\mathrm{M}$, et al. Ruxolitinib versus best available therapy in patients with polycythemia vera: 80-week follow-up from the RESPONSE trial. Haematological. 2016;101(7):821-829.

72. Passamonti F, Griesshammer M, Palandri F, et al. Ruxolitinib for the treatment of inadequately controlled polycythaemia vera without splenomegaly (RESPONSE-2): a randemised, open-label, phase $3 \mathrm{~b}$ study. Lancet Oncol. 2017;18(1):88-99.

73. Harrison CN, Mead AJ, Panchal A, et al. Ruxolitinib vs best available therapy for et intolerant or resistant to hydroxycarbamide. Blood. 2017;130(17):1889-1897.

74. Gunawan A, Harrington P, Garcia-Curto N, McLornan D, Radio D, Harrison C. Ruxolitinib for the Treatment of Essential Thrombocythemia. HemiSphere. 2018;2 (4):e56.

75. Harrison CN, McLornan DP. Current treatmont algorithm for the management of patients with myelofibrosis, JAK inhibitors, and beyond. Hematology Am Soc Hematol Educ Program. 2017;2017(1):489-497.

76. Bose P, Gotlib J, Harrison CN, Verstovsek S. SOHO State-of-the-Art Update and Next Questions: MPN. Clip Lymphoma, Myeloma Leek. 2018;18(1):1-12.

77. Tremblay D, Mascarenhas J. Pacritinib to treat myelofibrosis patients with thrombocytopenia. Expert Rev Hematol. 2018;11(9): 707-714.

78. Harrington PM, Harrison CN. Beyond JAK2: potential targets for myeloproliferative neoplasm therapy. Expert Rev Hematol. 2018;11(4):315-324.

79. Kremyanskaya M, Hoffman R, Mascarenhas J, et al. A Phase 2 Study of Cpi-0610, a Bromodomain and Extraterminal (BET) Inhibitor, in Patients with Myelofibrosis (MF). Blood. 2018;132(Suppl 1):5481.

80. Quintás-Cardama A, Kantarjian H, Estrov Z, Borthakur G, Cortes J, Verstovsek S. Therapy with the histone deacetylase inhibitor pracinostat for patients with myelofibrosis. Leek Res. 2012;36(9):11241127.

81. DeAngelo DJ, Tefferi A, Fiskus W, et al. A phase II trial of panobinostat, an orally available deacetylase inhibitor (DACi), in patients with primary myelofibrosis (PMF), post essential thrombocythemia (ET), and post polycythemia vera (PV) myelofibrosis. Blood. 2010;116(21):630.

82. Mesa RA, Vannucchi AM, Mead A, et al. Pacritinib versus best available therapy for the treatment of myelofibrosis irrespective of baseline cytopenias (PERSIST-1): an international, randomised, phase 3 trial. Lancet Haematol. 2017;4(5):e225-e236.

83. Mascarenhas J, Hoffman R, Talpaz M, et al. Pacritinib vs best available therapy, including ruxolitinib, in patients with myelofibrosis: A randomized clinical trial. JAMA Oncol. 2018;4(5):652-659.

84. Mesa RA, Kiladjian JJ, Catalan JV, et al. Simplify-1: A phase III randomized trial of momelotinib versus ruxolitinib in janus kinase inhibitor-naïve patients with myelofibrosis. J Chin Oncol. 2017;35(34):3844-3850.

85. Harrison CN, Vannucchi AM, Platzbecker $\mathrm{U}$, et al. Momelotinib versus best available therapy in patients with myelofibrosis ereviously treated with ruxolitinib (SIMPLIFY 2): a randomised, open-label, phase 3 trial. Lancet Haematol. 2018;5(2):e73-e81.

86. Pardanani A, Harrison C, Cortes JE, et al. Safety and efficacy of fedratinib in patients with primary or secondary myelofibrosis: A randomized clinical trial. JAMA Oncol. 2015;1(5):643-651.

87. Harrison CN, Schaap N, Vannucchi AM, et al. Janus kinase-2 inhibitor fedratinib in patients with myelofibrosis previously treated with ruxolitinib (JAKARTA-2): a singlearm, open-label, non-randomised, phase 2, multicentre study. Lancet Haematol. 2017;4(7):e317-e324.

88. Harrison CN, Mesa RA, Jamieson C, et al. Case series of potential wernicke's encephalopathy in patients treated with fedratinib. Blood. 2017;130(Suppl 1):4197.

89. Valentin R, Grabow S, Davids MS. The rise of apoptosis: Targeting apoptosis in hematologic malignancies. Blood. 2018;132(12): 1248-1264.

90. McArthur K, Chappaz S, Rile BT. Apoptosis in megakaryocytes and platelets: the life and death of a lineage. Blood. 2018;131(6):605610.

91. Baerlocher GM, Oppliger Leibundgut E, Ottmann OG, et al. Telomerase Inhibitor Imetelstat in Patients with Essential Thrombocythemia. N Angl J Med. 2015;373 (10):920-928

92. Tefferi A, Lasho TL, Begna KH, et al. A Pilot Study of the Telomerase Inhibitor Imetelstat for Myelofibrosis. N Engl J Med. 2015;373(10):908-919.

93. Mascarenhas J, Komrokji RS, Cavo M, et al. Imetelstat Is Effective Treatment for Patients with Intermediate-2 or High-Risk Myelofibrosis Who Have Relapsed on or Are Refractory to Janus Kinase Inhibitor Therapy: Results of a Phase 2 Randomized Study of Two Dose Levels. Blood. 2018;132(Suppl 1):685

94. Kuykendall A, Wan Y, Mascarenhas J, et al. Favorable overall survival of imetelstat-treated relapsed/refractory myelofibrosis patients compared with closely matched real world data: PS1456. HemaSphere. 2019;3:669-670.

95. Mascarenhas J, Lu M, Kosiorek H, et al. Oral Idasanutlin in Patients with Polycythemia Vera. Blood. 2019;134(6):525-533.

96. Lu M, Xii L, Salami ME, Hoffman R. Combination Treatment with an MDM2 Antagonist and a BET Inhibitor Targets Both Myelofibrosis Hematopoietic Stem/

Promoting Microenvironment. Blood. 2017;130(Suppl 1):4225.

97. Kvasnicka HM, Thiele J, Bueso-Ramos CE, et al. Ruxolitinib-Induced Modulation of Bone Marrow Microenvironment in Patients with Myelofibrosis Is Associated with Inflammatory Cytokines Levels. Blood. 2014;124(21):3182.

98. Hasserjian RP, Gotlib J, Cortes JE, et al. Effect Of Treatment With The JAK2-Selective Inhibitor Fedratinib (SAR302503) On Bone Marrow Histology In Patients With Myeloproliferative Neoplasms With Myelofibrosis. Jamieson CHM, ed. Blood. 2013;122(21):2823.

99. Jamieson C, Hasserjian R, Gotlib J, et al. Effect of treatment with a JAK2-selective inhibitor, fedratinib, on bone marrow fibrosis in patients with myelofibrosis. J Transl Med. 2015;13(1):294.

100. Verstovsek S, Mesa RA, Foltz LM, et al. PRM-151 in Myelofibrosis: Durable Efficacy and Safety at 72 Weeks. Blood. 2015;126 (23):56.

101. Verstovsek S, Hasserjian RP, Pozdnyakova O, et al. PRM-151 in Myelofibrosis: Efficacy and Safety in an Open Label Extension Study. Blood. 2018;132(Suppl 1):686

102. Verstovsek S, Talpaz M, Wadleigh M, et al. A randomized, double blind phase 2 study of 3 different doses of prm-151 in patients with myelofibrosis who were previously treated with or ineligible for ruxolitinib: S828. HemiSphere. 2019;3(S1):S829.

103. Times R, Mesa RA. Targeting hedgehog signaling in myelofibrosis and other hematologic malignancies. J Hematol Oncol. 2014.

104. Sasaki K, Gotlib JR, Mesa RA, et al. Phase II evaluation of IPI-926, an oral Hedgehog inhibitor, in patients with myelofibrosis. Leuk Lymphoma. 2015;56(7):2092-2097.

105. Gupta V, Koschmieder S, Harrison CN, et al. Phase $1 b$ Dose-Escalation Study of Sonidegib (LDE225) in Combination with Ruxolitinib (INC424) in Patients with Myelofibrosis. Blood. 2014;124(21):712.

106. Mesa RA, Tefferi A, Elliott MA, et al. A phase II trial of pirfenidone (5-methyl-1phenyl-2-[1H]-pyridone), a novel antifibrosing agent, in myelofibrosis with myeloid metaplasia. $\mathrm{Br} \mathrm{J}$ Haematol. 2001;114(1):111-113.

107. Mascarenhas J, Li T, Sandy L, et al. Antitransforming growth factor- $\beta$ therapy in patients with myelofibrosis. Leak Lymphoma. 2014;55(2):450-452.

108. Ye L, Bartenstein M, Zhao W, et al. Preclinical Efficacy of TGF-Beta Receptor I Kinase Inhibitor, Galunisertib, in Myelofibrosis. Blood. 2015;126(23):603.

109. Verstovsek S, Savona MR, Mesa RA, et al. A phase 2 study of simtuzumab in patients with primary, post-polycythaemia vera or post-essential thrombocythaemia myelofibrosis. Br J Haematol. 2017;176(6):939-949.

110. Masarova L, Verstovsek S, Hidalgo-Lopez JE, et al. A phase 2 study of ruxolitinib in combination with azacitidine in patients with myelofibrosis. Blood. 2018;132 (16):1664-1674.

111. Herlihy N, Harrison CN, McLornan DP. Exploitation of the neural-hematopoietic stem cell niche axis to treat myeloproliferarive neoplasms. Haematological. 2019;104(4):639-641.

112. Drexler B, Passweg JR, Tzankov A, et al. The sympathomimetic agonist mirabegron did not lower JAK2-V617F allele burden, but restored nestin-positive cells and reduced reticulin fibrosis in patients with myelopro- 
liferative neoplasms: results of phase II study SAKK 33/14. Haematologica. 2019;104(4):710-716.

113. Mesa RA, Silver RT, Verstovsek S, et al. Single agent bevacizumab for myelofibrosis: Results of the myeloproliferative disorders research consortium trial. Haematologica. 2013;98(9):1421-1423.

114. Giles FJ, List AF, Carroll M, et al. PTK787/ZK 222584, a small molecule tyrosine kinase receptor inhibitor of vascular endothelial growth factor (VEGF), has modest activity in myelofibrosis with myeloid metaplasia. Leuk Res. 2007;31(7):891-897.

115. Hermouet S, Bigot-Corbel E, Gardie B. Pathogenesis of Myeloproliferative Neoplasms: Role and Mechanisms of
Chronic Inflammation. Mediators Inflamm. 2015;2015:145293.

116. Baumeister J, Chatain N, Hubrich A, et al. Implication of Hypoxia-Inducible Factor-1 (HIF-1) As a New Therapeutic Target in JAK2-V617F Positive Myeloproliferative Neoplasms (MPN). Blood. 2018;132(Suppl 1):4318.

117. Xia Y, Choi H-K, Lee K. Recent advances in hypoxia-inducible factor (HIF)-1 inhibitors. Eur J Med Chem. 2012;49:24-40.

118. Barosi G, Gattoni E, Guglielmelli P, et al. Phase I/II study of single-agent bortezomib for the treatment of patients with myelofibrosis. Clinical and biological effects of proteasome inhibition. Am J Hematol. 2010;85 (8):616-619.
119. Mascarenhas J, Sandy L, Lu M, et al. A phase II study of panobinostat in patients with primary myelofibrosis (PMF) and post-polycythemia vera/essential thrombocythemia myelofibrosis (post-PV/ET MF). Leuk Res. 2017;53:13-19.

120. Kleppe M, Koche R, Zou L, et al. Dual Targeting of Oncogenic Activation and Inflammatory Signaling Increases Therapeutic Efficacy in Myeloproliferative Neoplasms. Cancer Cell. 2018;33(1):2943.e7.

121. Mascarenhas J, Navada S, Malone A, Rodriguez A, Najfeld V, Hoffman R. Therapeutic options for patients with myelofibrosis in blast phase. Leuk Res. 2010;34(9):1246-1249. 